\title{
Viabilidade econômica da erva-mate em propriedade da fronteira Brasil/Paraguai, estado de Mato Grosso do Sul
}

Diante da potencialidade econômica natural e concentração ainda tímida de pequenos e médios produtores de erva-mate dispersos na região sul de Mato Grosso do Sul, o presente estudo objetivou analisar a viabilidade econômica da exploração de erva-mate em propriedade localizada naquela região. Através de questionário e visitas in loco, considerou-se uma propriedade amostral de 8 ha localizada no município de Amambai-MS, fronteira Brasil e Paraguai, que possui atualmente, manejo e produção de erva-mate em 2 ha, com informações desde o plantio, primeira poda ( 3,5 anos) e segunda poda ( 5,5 anos) e estimados os valores de fluxo de caixa para os anos subsequentes. Foram obtidos dados da segunda poda quanto às variáveis: custos de implantação, manutenção, equipamentos, mão de obra, transporte e demais fatores pertinentes à produção e comercialização do produto final. A análise econômica baseou-se no cálculo de implantação, manutenção, equipamentos, mão de obra, transporte e demais fatores pertinentes à produção e comercialização do produto final. A análise econômica baseou-se no cálculo exigidos legalmente para o manejo e dimensão da produção, os valores extraídos somaram-se aos Custos Operacionais Totais (COT). A análise de viabilidade econômica perante os investimentos foi associada ao fluxo de caixa, permitindo identificar as respectivas saídas e entradas de recursos, descontadas a uma Taxa Mínima de Atratividade (TMA), em comparação com a remuneração mínima de $20 \%$ a.a. esperada pelo proprietário. Os resultados mostraram viabilidade econômica da erva-mate para o empreendimento rural em foco, com percentuais expressos na lucratividade ( $L L=25,85 \%$ a.a. e TIR $=21,61 \%$ a.a. e TMA $20 \%$ a.a.). No entanto, a viabilidade econômica deve ser pensada como uma atividade alternativa, uma vez que o cultivo é considerado como investimento ex-post, ou seja, com tempo relativamente longo de retorno e suscetível a diversos fatores, tanto endógenos como exógenos.

\section{Economic viability of yerba-mate in a rural property of Brazil/Paraguay border, Mato Grosso do Sul state}

\begin{abstract}
In view of the natural economic potential and the still timid concentration of small and medium producers of yerba mate dispersed in the southern region of Mato Grosso do Sul, the present study aimed to analyze the economic viability of yerba mate exploration in a property located in this region. Through questionnaire and on-site visits, we considered an 8-ha sample property located in the municipality of Amambai-MS, on the border between Brazil and Paraguay, with current yerba mate management and production in 2 ha, comprising information since planting first pruning ( 3.5 years) and second pruning ( 5.5 years), and estimated cash flow values for subsequent years. Data from the second pruning were obtained regarding the following variables: implementation costs, maintenance, equipment, labor, transportation and other factors relevant to the production and marketing of the final product. Economic analysis was based on the
calculation of the Net Present Value (NPV) and Internal Rate of Return (IRR) related to results obtained by calculating effective operating costs (COE) declared by the owner, and costs required calculation of the Net Present Value (NPV) and Internal Rate of Return (IRR) related to results obtained by calculating effective operating costs (COE) declared by the owner, and costs required
legally for the production size and management; values extracted were added to Total Operating Costs (COT). The economic viability analysis of investments was associated with cash flow, allowing to identify the respective resource outflows and inflows, which were discounted at a Minimum Attractiveness Rate (TMA) in comparison with the minimum remuneration of $20 \%$ p.a. expected by the owner. Results showed the economic viability of yerba mate for the researched rural enterprise, with percentages pointing to profitability (LL $=25.85 \% / \mathrm{yr}$ and IRR $=$ $21.61 \% / y r$ and TMA $20 \% / y r)$. However, once cultivation is considered an ex-post investment, that is, with relatively long return time and susceptible to several factors, both endogenous and exogenous, economic viability must be thought of as an alternative activity.
\end{abstract}

Keywords: Ilex paraguariensis St. Hil; Production and Income Alternatives; Agroforestry Management; Small Farmers Municipality of Amambai, MS.

Topic: Desenvolvimento, Sustentabilidade e Meio Ambiente

Reviewed anonymously in the process of blind peer.

Romildo Camargo Martins (iD

Universidade Católica Dom Bosco, Brasil

http://lattes.cnpq.br/3446894276755097

http://orcid.org/0000-0001-9811-8311

romldocamargo@gmail.com

Márcio Aquino dos Santos (id

Universidade Estadual de Mato Grosso do Sul, Brasil

http://lattes.cnpq.br/0408427175618959

http://orcid.org/0000-0002-6424-1992

mar.aqui.santos@gmail.com

\section{Rildo Vieira de Araújo (iD}

Universidade Católica Dom Bosco, Brasil

http://lattes.cnpq.br/8724163396459735

http://orcid.org/0000-0002-8748-0080

ifmt.rildo@gmail.com

d

DOI: 10.6008/CBPC2179-6858.2021.006.0043
Received: 06/06/2021

Approved: 28/06/2021

\begin{abstract}
Micaella Lima Nogueira (iD
Universidade Católica Dom Bosco, Brasil http://lattes.cnpq.br/7157513037037360 http://orcid.org/0000-0001-8371-2772

mican1805@gmail.com

Rafael Mamoru dos Santos Yui

Universidade Católica Dom Bosco, Brasil

http://lattes.cnpq.br/1491483495039895

http://orcid.org/0000-0003-2729-0696

rafayui99@gmail.com

Reginaldo Brito Costa (iD)

Universidade Católica Dom Bosco, Brasil

http://lattes.cnpq.br/5482602985686580

http://orcid.org/0000-0002-5677-393X

reg.brito.costa@gmail.com
\end{abstract}

\section{Referencing this:}

MARTINS, R. C.; SANTOS, M. A.; ARAÚJO, R. V.; NOGUEIRA, M. L.; YUI, R. M. S.; COSTA, R. B.. Viabilidade econômica da erva-mate em propriedade da fronteira Brasil/Paraguai, estado de Mato Grosso do Sul. Revista Ibero Americana de Ciências Ambientais, v.12, n.6, p.522534, 2021. DOI: http://doi.org/10.6008/CBPC2179-

6858.2021.006.0043 


\section{INTRODUÇÃO}

Ao se analisar os sistemas agroflorestais, bem como as atividades inerentes a exploração e manejo de lavouras permanentes ${ }^{1}$, duas vertentes de importantes considerações surgem nesse contexto, sendo o planejamento e o controle. Para Batalha (2008) o planejamento decidirá sobre os objetivos, neste caso, as condições e ações para atingir esses objetivos, com isso, o controle vem de encontro ao monitoramento das ações reais, verificando a compatibilidade com o que foi planejado e demonstrando os desvios ocorridos. Por outro lado, a falta de planejamento e controle possui consequência direta na gestão com um elevado nível de desperdício e perda de rentabilidade.

Nessa temática, designa-se ao termo erva-mate, tanto a planta llex paraguariensis St. Hil. ${ }^{2}$ como o produto ainda in natura que se obtém do processo de transformação de suas folhas e ramos (KREUZ et al., 2005). Classificada como Produto Florestal Não Madeireiro (PFNM) ${ }^{3}$, a erva-mate constitui o maior volume de produção dessa categoria em todo o território nacional, valorando, segundo dados do IBGE para o ano de 2017, uma produção de 973.401t (IBGE, 2017) em todo o país, visto que no Mato Grosso do Sul estas produções no mesmo período alcançou 1.621t. Por isso, frente às potencialidades endógenas, tornam-se cada vez mais importante buscar oportunidades e alternativas para a geração de renda e emprego, bem como o aproveitamento assertivo das potencialidades locais, para as políticas e ações no que tange o desenvolvimento da região, especificamente o sul de Mato Grosso do Sul.

De forma gradativa, o cultivo da erva-mate vem ganhando seu destaque no estado sul-matogrossense, mais precisamente na região sul do estado, considerada como um importante corredor de ocorrência natural da espécie nativa. De forma geral, a presença da erva-mate se dá naturalmente em regiões subtropicais e temperadas da América do Sul, com distribuição a partir da região central do Rio Grande do Sul, estendendo-se em todo o estado de Santa Catarina, bem como o centro sul do Paraná e uma pequena parte do nordeste de São Paulo, do estado do Paraná a espécie perpassa parte da Argentina, Paraguai e o sul de Mato Grosso do Sul (DANIEL, 2009; DALLABRIDA, 2014; CIMÓ, 2015).

No agronegócio, o cultivo da erva-mate, Kreuz et al. (2005) afirmam que "é importante que se diferencie a erva-mate plantada da erva-mate nativa. Enquanto a primeira é oriunda de ervais plantados em terrenos após o mesmo ter sido limpo, a erva-mate nativa é resultado da exploração dos pés existentes na vegetação natural”. Inseridos nessa conjuntura econômico-produtiva os três estados da região Sul do País (Rio Grande do Sul, Santa Catarina e Paraná) se destacam na participação nacional, contabilizando um total de $971.780 t$ de folhas verdes (IBGE, 2017). Sendo, Lavouras Permanentes: Paraná (237.476t), Santa Catarina (78.078t) e Rio Grande do Sul (302.000t) e Extração Vegetal: Paraná (301.813), Santa Catarina (35.250) e Rio Grande do Sul (17.163) com predomínio.

Diante da potencialidade econômica natural e a concentração de pequenos e médios produtores de

\footnotetext{
1 Área plantada ou em preparo para plantio de longa duração, isto é, aquela que após a colheita não necessitam de novo plantio, produzindo por vários anos consecutivos (epagri.sc.gov.br).

${ }^{2}$ Referência dada ao nome do naturalista francês August de Saint-Hilaire que no ano de 1820 empreendeu várias missões no sul do Brasil para relatar à França as espécies de ervais sulistas (DANIEL, 2009).

${ }^{3}$ Produtos de origem biológica que podem ser colhidos na natureza, derivados de florestas como nozes comestíveis, cogumelos, frutas, ervas (FAO, 2015).
} 
erva-mate ainda bastante tímida, dispersa na região sul de Mato Grosso do Sul e da ainda carência de informações sobre a temática, o respectivo estudo objetivou demonstrar a possível viabilidade de exploração da espécie Ilex paraguariensis St. Hil. economicamente em 2 ha $\left(20.000 \mathrm{~m}^{2}\right)$ como uma alternativa de renda e geração de empregos a partir de uma propriedade de 8 hectares (ha) no município de Amambai ${ }^{4}$.

\section{REVISÃO TEÓRICA}

\section{A erva-mate e seu aspecto histórico e socioeconômico no MS}

A Ilex paraguariensis St. Hil. como é catalogada cientificamente a erva-mate, já era plantada e utilizada pelos indígenas do Novo Mundo ${ }^{5}$, que chamavam de caá, que traduzindo do Guarani, significa erva (BIANCHINI, 2000). A utilização da erva-mate como alimento é carregada de costumes entre os índios Guaranis, passou a se propagar e disseminar junto aos envolvidos na exploração dos ervais nativos das cidades localizadas no Sul do antigo Mato Grosso que sempre fez fronteira com a cidade de Pedro Juan Caballero no Paraguai.

É fato que no limiar do processo desenvolvimentista do antigo estado de Mato Grosso, as regiões foram sendo marcadas por distintas manifestações culturais e de integração entre os povos latinos da Bolívia e com mais intensidade do Paraguai para com esta ponta do Brasil. Entre os elementos de maior compartilhamento social e econômico nesta multiplicidade territorial está a erva-mate, constituída de um grande enredo integrador que também passou a ser um dos marcos de diferentes conflitos locais. Para Abinzano (2010) "el frente extractivo impulso el surgimiento de una serie de epifenómenos [...] económicos, políticos, sociales y culturales como ocurre en las sociedades pioneras donde los actores se ven compelidos a una multiplicidad de tareas que abarcan un espectro muy amplio de locus sociales".

Neste sentido, é com a atuação ativa e empírica da tribo paraguaia dos Guarani-Kaiowa ${ }^{6}$ (cuja língua se apresenta como a segunda deste país), que a exploração dos ervais nativos ganha força no sul do antigo Mato Grosso, especificamente em fins do século XIX (DANIEL, 2009). Logo após a guerra do Paraguai ou Guerra da Tríplice Aliança (1864-870) ${ }^{7}$, a exploração da erva-mate ganha destaque, se tornando uma espécie de "ouro verde" conforme afirma Daniel (2009), na região sul do antigo Mato Grosso, mais precisamente em Ponta Porã, Amambaí e Pedro Juan Caballero, esta última situada do lado paraguaio. Grandes empresas passam a migrar para a região com o objetivo de assumir a exploração dos ervais que na época fomentou grande parte da economia brasileira. Nisso, Bianchini (2000) vai dizer que as ações deliberativas para a exploração dos ervais dependiam do ponto de vista de cada governante na região, para alguns a melhor opção era a concessão às empresas privadas e para outros era mais indicada a intervenção do estado, problema que vinha se arrastando também pela conjuntura econômica do pós-guerra.

\footnotetext{
${ }^{4}$ Localizada a 359 km de Campo Grande (capital do MS), o a cidade localiza-se no sul da região Centro-Oeste do Brasil à Sudoeste de Mato Grosso do Sul (Microrregião de Dourados) e próximo da fronteira com o Paraguai (cidades.ibge.gov.br).

${ }^{5}$ Nome dado à América pelos colonizadores e exploradores europeus no século XV e XVI (GRESSLER et al., 2005)

${ }^{6}$ População indígena considerada pacífica que habitavam a região paraguaia (hoje Pedro Juan Caballero) e fronteira com Ponta Porã-MS (COMÊU, 1977, citado por BIACHINI, 2000).

7 “Devido a Aliança de guerra assinada entre o Brasil, Argentina e Uruguai para enfrentar o então presidente paraguaio Francisco Solano Lopez entre 1864 e 1870" (GRESSLER et al., 2005).
} 
Neste cenário, destaca-se no processo extrativista e mercantil dos ervais sul mato-grossense Thomaz Laranjeira, fundador da icônica Companhia Matte Larangeira ${ }^{8}$. A participação de Thomaz Laranjeira na comissão demarcadora para estabelecer os limites entre Brasil e Paraguai depois da guerra no ano de 1872. Este fato foi decisivo para aumentar o interesse na atividade (FRÓES, 2007) e posteriormente receber, por meio de decreto Imperial $^{9}$, concessão para a livre exploração dos ervais na região a partir do ano de 1882, onde até mesmo a paisagem da região sofreria alterações com esta iniciativa.

Com efeito, mais tarde, a expansão e o fortalecimento da Companhia Matte Larangeira, a torna detentora da extração da erva-mate no sul do estado, tornando-se assim responsável, conforme Daniel (2009), pela fundação de cidades, vilas, aglomerados urbanos e até escolas. Pode-se considerar nesse sentido a ocorrência de uma dinâmica própria e rentável na região, que segundo Cimó (2015), se deve ao fato de que a exploração ervateira foi bastante lucrativa economicamente no então Mato Grosso no início de 1890, por ter a característica de um produto de boa qualidade, também tinha como principal consumidor e fiel comprador a Argentina.

\section{A erva-mate no estado Sul-Mato-Grossense: avanços e desafios}

Mato Grosso do Sul possui em sua conjuntura econômico-produtiva uma forte base no agronegócio, especificamente na produção e escoamento de grãos - destacando-se nesse aspecto a soja e o milho. Por outro lado, a silvicultura passou a assumir uma visão de oportunidade na geração de renda e emprego, mais precisamente na exploração do eucalipto para as grandes indústrias de papel e celulose. Segundo dados extraídos do IBGE - PEVS para o ano de $2017^{9}$, a madeira em tora para papel e celulose oriunda do estado sul-mato-grossense contribuiu com um total de $12.860 .798 \mathrm{~m}^{3}$ do montante nacional, que alcançou nesse período um resultado de $87.739 .560 \mathrm{~m}^{3}$ de eucalipto/madeira para este fim, dando destaque aos municípios produtores: Aparecida do Taboado, Três Lagoas, Brasilândia, Ribas do Rio Pardo, Água Clara, Bataguassu, Inocência, Jaguari, Nova Andradina, Santa Rita do Pardo e Selvíria.

Não obstante, o IBGE ainda destaca que a exploração ervateira no estado se encontra expressivamente distribuída entre os municípios de Amambai, Aral Moreira e Ponta Porã, bem como em alguns municípios como Rio Verde, Tacuru e Paranhos, contabilizando uma participação de apenas 0,23\% do total produzido no país conforme análise da Tabela 1.

Tabela 1: Valores em quantidade produzida, valor da produção, área colhida e rendimento da erva-mate (em folha verde).

\begin{tabular}{lllll}
\hline \multicolumn{4}{l}{ Quantidade produzida, valor da produção, área colhida e rendimento médio da erva-mate (em folha verde), Ano 2017. } \\
\hline Nacional, Região e Estados & Qtde produzida (ton) & Valor da prod. (R\$) & Área colhida (ha) & \multicolumn{1}{c}{ Rendimento médio kg/ha } \\
Brasil & 619.003 & 501.633 .000 & 75.662 & $8.181,16$ \\
PR & 237.476 & 254.847 .000 & 33.231 & $7.146,21$ \\
SC & 78.078 & 45.982 .000 & 11.523 & $6.775,83$ \\
RS & 302.000 & 199.935 .000 & 30.640 & $9.856,39$ \\
Sul & 617.554 & 500.764 .000 & 75.394 & $8.191,02$ \\
MS & 1.449 & 869.000 & 268 & $5.406,71$
\end{tabular}

Fonte: Lavouras Permanente (IBGE, 2017).

\footnotetext{
8 "Estabelecida em Porto Murtinho, a companhia juntamente com "os Murtinhos", políticos tradicionais da época, dão nome a cidade, bem como ao porto ali situado para o escoamento da produção" (GRESSLER, et al., 2005).

${ }^{9}$ Produção da Extração Vegetal e da Silvicultura - PEVS 2017, contemplando informações referentes à quantidade e ao valor da produção decorrente dos processos de exploração dos recursos vegetais naturais (extrativismo vegetal), bem como da exploração dos maciços florestais plantados (silvicultura).
} 
Frente aos indicadores do IBGE relativo à produção de erva-mate no MS em 2017, os dados apresentam uma área colhida de 268 hectares de erva-mate com a produção de 1.449 toneladas de folhas verdes, atingindo o valor de produção de $\mathrm{R} \$ 869.000,00$. A produtividade financeira caracterizou por hectare um total de $\mathrm{R} \$ 3.242,53^{10}$, considerando o valor médio de $\mathrm{R} \$ 8,99^{11}$ a arroba de folhas verdes no estado abaixo da média nacional - dentro do período analisado, corroborando assim, com mais de $5.400 \mathrm{Kg} / \mathrm{ha}$ no que tange ao rendimento médio de produção, número que expressa o tímido e constante crescimento para a média de rendimento dos demais estados produtores líderes de erva-mate.

É certo que o atrativo das grandes lavouras de soja e milho e a cadeia já consolidada, determinam na maioria das vezes o desinteresse por parte de alguns produtores rurais da exploração de PFNM em especial a erva-mate. Shaeffer (2003) corrobora dizendo que desde a década de 1970, com a expansão das atividades agropastoris, grandes maciços florestais do estado foram suprimidos, sem nenhum critério técnico ou preocupação ambiental. De certa forma as transformações no sistema agroindustrial ${ }^{12}$ são constantes e muitas vezes incertas. Batalha (2008) considera estas transformações como o resultado de deslocamento das fronteiras do sistema, mudança no meio ambiente ou nos rearranjos interno dos subsistemas que formam o sistema principal.

Ao longo do tempo, as transformações foram ocorrendo no agronegócio sul-mato-grossense, perdendo ou desestruturando a cadeia produtiva da erva-mate. Assim, as inovações tecnológicas surgem como um fator modificador das principais cadeias produtivas (BATALHA, 2008). Esta é uma realidade no que refere à cadeia produtiva da erva mate em Mato Grosso do Sul, de forma distinta do que ocorreu em regiões melhores estruturadas em sua forma sociocultural, como é o caso da região Sul do Brasil.

\section{MATERIAIS E MÉTODOS}

Na conviç̧ão de que as ciências devem se caracterizar pela utilização de métodos científicos, uma vez que, conforme argumentam Marconi et al. 2011) "não há ciência sem o emprego de métodos científicos". Dessa forma, a modalidade de pesquisa adotada foi o estudo de caso, caracterizado por investigação empírica, compreendendo uma lógica de planejamento desde a coleta à análise dos dados. Além disso, permite sua aplicação em estudos de caso único ou múltiplos casos, mediante abordagens quantitativas e/ou qualitativas (YIN, 2001). Neste sentido, esta modalidade, permite ao pesquisador a adoção de uma metodologia que contemple a sua necessidade de verificação ou avalições específicas.

A escolha do lócus da pesquisa se justifica, uma vez que a região sul-mato-grossense tem em suas raízes de formação histórica econômica a presença da cultura da erva-mate como principal produto de sua economia, conforme anteriormente observado. Desta forma, para atender ao propósito de pesquisa, identificou-se uma propriedade localizada na área rural do município de Amambai/MS (latitude: 23 6' 10"

\footnotetext{
10 Valor referente à divisão do valor total da produção do estado de Mato Grosso do Sul pela área total colhida do estado referente ao ano de 2017, sendo: $\mathrm{R} \$ 869.000 / 268$ ha=R\$3.242,53. Considerando nesse sentido valor médio de $\mathrm{R} \$ 12,16$ a arroba de folhas verdes para o ano de 2017 em âmbito nacional, sendo: (R\$501.633,000/619.003/1000*15).

${ }^{11}$ Valor referente à divisão do valor da produção total do MS pela quantidade total produzida no período, sendo: (869.000/1.449/1000*15).

${ }^{12} \mathrm{SAl}$ - considerado o conjunto de atividades que concorrem para a produção de produtos agroindustriais, desde a produção dos insumos (sementes, adubos, máquinas etc.) até a chegada do produto final (queijo, biscoito, massa etc.) ao consumidor (BATALHA, 2008).
} 
Sul, longitude: $55^{\circ} 13^{\prime} 15^{\prime \prime}$ Oeste e altitude de 477 metros), dispõe de toda a estrutura necessária para a produção de erva-mate em modo semi-industrial (mantêm, em algumas etapas, características de produção artesana $\left.\right|^{13}$ ). Além disso, o estudo concentrou na análise de área de 2 hectares de erva-mate, abrangendo desde o plantio, primeira poda (aos 3,5 anos) e segunda poda (aos 5,5 anos).

A coleta de dados, observações e diálogos em campo ocorreram no mês de setembro de 2018, obtendo informações sobre o ciclo operacional - suas etapas, respectivos custos, despesas e resultados desde a colheita da matéria prima, secagem, trituração, moagem e empacotamento. 0 ciclo operacional envolve atividades desenvolvidas de forma sequencial e repetitiva, a produção de bens e serviços, estocagem, vendas e respectivos recebimentos, Assaf Neto et al. (2014) definem o ciclo operacional como sendo as atividades operacionais desenvolvidas, "de forma sequencial e repetitiva, a produção de bens e serviços, estocagem, vendas e respectivos recebimentos". Em tais operações básicas, a empresa procura alcançar determinado volume de lucros, que atendam suas expectativas de retorno sobre o capital investido (ASSAF NETO et al., 2014).

O resultado das atividades operacionais da empresa, necessariamente deve levar em conta os encargos que suporta para assegurar o exercício de sua atividade (matérias-primas, energia, salários, amortizações, provisões, etc.). Tais custos podem ser classificados em Custo Operacional Efetivo (COE), os quais correspondem aos desembolsos efetivamente realizados e destinados a compra de insumos necessários à produção e/ou a comercialização de produtos. Da mesma forma o COT (Custo Operacional Total) que representa a soma do COE às depreciações de bens e a remuneração do capital. Desta forma, o levantamento dos custos, configura-se em um método de avaliação do desempenho econômico e técnico relacionado a atividade produtiva ${ }^{14}$ (SIMÕES et al., 2007).

Para o cálculo do custo operacional efetivo (COE), foram contabilizados os gastos incidentes na produção: custo da matéria-prima própria (aquisição das mudas e manejo até o período de corte), mão de obra direta, energia, frete e outros. O cálculo do valor da mão de obra foi efetuado considerando o preço médio praticado na região, para o ano de análise, 2018. Após apurar o COE, acrescentou-se o cálculo estimado para a depreciação e juros de custeio, se houver, consubstanciando-se no custo operacional total (COT).

Nos encargos sociais foram considerados conforme a CLT (Consolidação das Leis do Trabalho), ou seja, $33 \%$ sob o montante do valor da mão de obra necessária, correspondente aos direitos trabalhistas (férias, 13ㅇ, INSS, etc.). A depreciação foi calculada, considerando o método linear e incide sobre as máquinas e equipamentos que compõem a estrutura produtiva da empresa. As despesas gerais consistiram dos seguintes gastos: sacarias; embalagens; rótulos e madeira para queima (lenha).

A sequência de avaliação ocorreu como segue: i) cálculo da Receita Bruta (RB), resultante da quantidade de vendas (QTDv) multiplicado pelo preço unitário do produto (Pu), ou seja, $\mathrm{RB}=\mathrm{QTDv} \times \mathrm{Pu}$; ii)

\footnotetext{
${ }^{13}$ Entre as etapas da produção de erva-mate, temos o trabalho executado pelos "sapecadores" que desenvolvem o sapeco manual, o qual é executado apenas no processamento artesanal, nas propriedades rurais (MACCARI JÚNIOR, 2005).

${ }^{14}$ Para efeito de cálculo de viabilidade econômica ressalta-se que este estudo não considerou o custo da variável "terra" (considerado como ativo fixo).
} 
O Lucro Operacional (LO) resulta da subtração da receita bruta e dos custos totais, assim expresso: LO = RB - COT; iii) O Índice de Lucratividade (IL) obtidos através da razão, o lucro operacional e a receita bruta, indicando a margem de lucro após a cobertura de todos os custos operacionais, expresso como segue: IL = (LO/RB) $\times 100$.

A análise de viabilidade econômica perante os investimentos deve ser associada a um fluxo de caixa, que permita identificar as respectivas saídas e entradas de recursos, descontadas a uma Taxa Mínima de Atratividade (TMA). Neste caso a remuneração mínima exigida pelo proprietário é de $20 \%$ a.a. Para auxiliar este entendimento é importante ressaltar a existência de estudos realizados acerca da viabilidade econômica da erva-mate que indicaram Taxa Interna de Retorno (TIR) de $29,57 \%$ a.a. conforme publicação da Revista Extensão Rural, frutos de pesquisa elaborada por Rodigheri et al. (2002).

Assim sendo, a sequência deste estudo exigiu a elaboração de um fluxo de caixa, consubstanciando em uma ferramenta controle das entradas e saídas de recursos. O qual posteriormente foi utilizado no desenvolvimento do cálculo do Fluxo de Caixa Descontado ${ }^{15}$ sendo que seu resultado objetiva calcular o tempo estimado para se obter a cobertura do capital investido na atividade.

A seguir elabora-se o Valor Presente Líquido VPL ou NPV (Net Present Value), o qual utiliza os princípios de matemática financeira, calculando o valor presente do fluxo de caixa do investimento (ASSAF NETO, 2001). Este método é também chamado de líquido, pois considera o fluxo total com as saídas (investimentos) e entradas (retornos) descontadas a uma taxa de atratividade, pois o valor real do capital investido não será o mesmo no momento do retorno. Sua fórmula é assim expressa:

$\mathrm{n}$

$$
V P L=\sum F C /(1+i)^{t}
$$

$t=0$

Onde: $\mathrm{VPL}=$ valor presente líquido; $\mathrm{FC}=$ fluxo de caixa; $\mathrm{t}=$ período de análise $; \mathrm{i}=$ taxa de desconto; $\mathrm{n}=$ número de fluxos.

A Taxa Interna de Retorno (TIR) faz a mesma analogia de cálculo do VPL, entretanto seu resultado é expresso em percentual (\%). Sua fórmula está assim estruturada: $T I R=\sum_{T=0}^{n} \frac{F n}{(1+i)^{n}}=0$

A Taxa Interna de Retorno (TIR) representa a taxa de desconto (taxa de juros) que iguala, num único momento, os fluxos de entrada com os de saída de caixa. Em outras palavras, é a taxa de juros que produz um NPV $=0$ (ASSAF NETO, 2001).

\section{RESULTADOS E DISCUSSÃO}

A propriedade possui estrutura para o processamento de $1.800 \mathrm{~kg}$ de erva-mate em peso bruto determinada pela capacidade de secagem no barbaquá ${ }^{16}$. 0 sítio já dispõe de: área plantada de 2 hectares

\footnotetext{
${ }^{15}$ O Fluxo de Caixa Descontado (FCD) foi constituído pelos seguintes componentes: fluxos esperados de caixa; taxa de desconto (taxa mínima de atratividade - TMA); horizonte de tempo das projeções. O FCD incorpora em um único momento todos esses parâmetros econômicos fundamentais da avaliação (ASSAF NETO et al., 2014).

${ }^{16}$ Consiste em um jirau ou grade de varas sobre forquilhas, onde se estende a erva-mate. De elaboração mais complexa, exigindo maior investimento por parte do ervateiro, passou a ser utilizado, sobretudo a partir do século XX. Nesse sistema as folhas não secavam diretamente sobre o fogo e o
} 
em produção; 1 depósito com 3,5m no pé direito e 5,5 $\mathrm{m}$ no ponto mais alto, coberto com telhas de zinco com isolante térmico, com área de $55 \mathrm{~m}^{2}$; 1 tambora ${ }^{17}$; 1 barbaquá; 1 moinho; 1 triturador; 1 sopradora; 1 hidrolavadora; 01 balança, 01 veículo utilitário e uma carreta pequena (tipo reboque).

Para esta estrutura, de capacidade limitada pelo volume de folhas e peso que comportam a estrutura do barbaquá, têm-se estimativas de custos, quando colocada em operação. A Tabela 2 a seguir, apresenta tais custos e respectivos valores correspondentes que incidem no processo.

Tabela 2: Etapas do processo, tempo estimado por processo, máquinas, equipamentos, número de pessoas e respectivos custos - (processamento de $1800 \mathrm{~kg}$ de erva-mate in natura).

\begin{tabular}{|c|c|c|c|c|c|c|}
\hline \multirow[b]{2}{*}{ 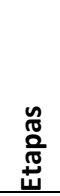 } & \multirow[b]{2}{*}{ Descrição da Operação } & \multirow[b]{2}{*}{$\begin{array}{l}\text { Tempo } \\
\text { estimado } \\
\text { (horas)* }\end{array}$} & \multicolumn{4}{|c|}{ CUSTOS ENVOLVIDOS } \\
\hline & & & $\begin{array}{l}\text { Energia(1) }^{(1)} \\
(\mathrm{R} \$)\end{array}$ & $\begin{array}{l}\text { N.o de pessoas } \\
\text { envolvidas no } \\
\text { processo } \\
\text { (Qtde)** }\end{array}$ & $\begin{array}{l}\text { Custo de mão } \\
\text { de obra }{ }^{(2)}(R \$)\end{array}$ & Outros \\
\hline 1. & $\begin{array}{l}\text { Corte, desbaste e transporte de } \\
\text { matéria prima - da lavoura ao pátio de } \\
\text { produção }\end{array}$ & 8 & - & 6 & 360,00 & $\begin{array}{l}00,00 \\
\text { ombustível (3) }\end{array}$ \\
\hline 2. & Sapeco das folhas & 2 & - & 8 & & 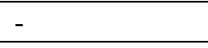 \\
\hline 3. & $\begin{array}{l}\text { Processamento de } 1800 \mathrm{~kg} \text { (peso } \\
\text { bruto - erva-mate sapecada) - } \\
\text { capacidade de um barbaquá - } \\
\text { estimativa de saída (input) de } 692 \mathrm{~kg}\end{array}$ & 15 & 15,00 & 2 & $200,00^{(4)}$ & $\begin{array}{l}75,00 \\
\text { ( } 4 \mathrm{~m} \text { de lenha) }\end{array}$ \\
\hline 4. & Cancheamento (5) & 3 & 138,40 & 2 & 45,00 & \\
\hline 5. & Tritu & 4 & 0 & 1 & 30 & \\
\hline 6. & Empaco & 30 & - & & 450,00 & \\
\hline \multicolumn{3}{|c|}{ Subtotais (=) } & $\mathrm{R} \$ 2$ & & & \\
\hline \multicolumn{7}{|c|}{ CUSTO TOTAL (R\$) $2.152,40$} \\
\hline $\begin{array}{l}\text { *As } \\
180 \\
\text { exig } \\
\text { aco } \\
* * \text { C } \\
\text { aco } \\
\text { aos } \\
* * * \\
\text { exp } \\
{ }^{1} \mathrm{O} \\
{ }^{2} \mathrm{Ut} \\
\text { da } \\
{ }^{3} \mathrm{Co} \\
{ }^{4} \mathrm{Ac} \\
{ }^{5} \mathrm{Eq} \\
\mathrm{X} \$ \mathrm{C} \\
{ }^{6} \mathrm{Cu} \\
\text { cálc }\end{array}$ & $\begin{array}{l}\text { operações incluíram: corte, desbaste, tr } \\
\text { kg (input), com produção estimada de } \\
\text { um sequenciamento, como é o caso d } \\
\text { do com a demanda prevista para entrega } \\
\text { número máximo de pessoas alocadas é } \\
\text { do com as necessidades de cada etapa. } \\
\text { barbaquazeiros". } \\
\text { Sob o cálculo da mão de obra necessár } \\
\text { essa nesta tabela. } \\
\text { dsto de energia para a "etapa 3" é fixo e } \\
\text { iza-se mão de obra contratada (diarista), } \\
\text { ária (\$)/8 horas X quantidade de hora/tr } \\
\text { siderando o mesmo percurso (km), o cu } \\
\text { escenta-se valor adicional ao "mestre erv } \\
\text { ipado com motor trifásico 4,0CV - } 2904 \mathrm{~V} \\
20 \text { / kg; } \\
\text { tos incidentes nesta etapa: embalagem } \\
\text { lo: } 692 \mathrm{~kg} X \text { R } \$ 0,55 \text { / kg. }\end{array}$ & $\begin{array}{l}\text { ansporte, sa } \\
592 \mathrm{~kg} \text { (outp } \\
\text { cancheame } \\
\text { do produto } \\
14 \text { - durant } \\
\text { Considera-se } \\
\text { io, deve-se } \\
\text { não se altera } \\
\text { a média de } \\
\text { abalho X qu } \\
\text { to de transp } \\
\text { ateiro" (R\$1 } \\
\text { - consumo } \\
\text { rótulo e dis }\end{array}$ & $\begin{array}{l}\text {, secagem, } \\
\text { considera-s } \\
\text { trituração } \\
\text { l. } \\
\text { processame } \\
\text { a efeito de } \\
\text { iderar a inc } \\
\text { dade de pes } \\
\text { é fixo, trat } \\
\text { 0) e tambér } \\
\text { mado em R } \\
\text { uição, send }\end{array}$ & $\begin{array}{l}\text { ncheamento e em } \\
\text { que algumas etapa } \\
\text { mesmo o empacot } \\
\text { o ocorre o rodízio } \\
\text { Iculo: } 14 \text { diárias ao } \\
\text { ência dos encargos } \\
\text { ào em estudo é de } \\
\text { as ocupadas; } \\
\text { e do custo com cor } \\
\text { oo auxiliar (R\$50,00 } \\
20 \text { / kg. Fórmula d } \\
\text { um valor aproxima }\end{array}$ & $\begin{array}{l}\text { pacotamento, par } \\
\text { s são independen } \\
\text { tamento, este últi } \\
\text { de colaboradores, } \\
\text { custo de } \$ \$ 60,00 \\
\text { sociais e trabalh }\end{array}$ & $\begin{array}{l}\text { um volume de } \\
\text { es, ou seja, não } \\
\text { no realizado de } \\
\text { alocando-os de } \\
\text { /dia + R\$200,00 } \\
\text { stas (33\%), não } \\
\text { te cálculo: Valor } \\
\text { am o barbaquá. } \\
\text { erva-mate seca } \\
\text { kg. Fórmula de }\end{array}$ \\
\hline
\end{tabular}

O volume de capital fixo investido na empresa é de aproximadamente $R \$ 81.558,40$. Este valor corresponde aos itens tangíveis que compõem uma estrutura de capital em uma organização empresarial, ou seja, são aqueles bens mantidos para o uso na produção ou fornecimento de mercadorias ou serviços, para aluguel a outros, ou mesmo para fins administrativos, os quais se espera utilizá-los por mais de um período - exemplo: terrenos, edifícios, máquinas e equipamentos, veículos, móveis e utensílios, etc. (LEITE 
et al., 2016). A mão de obra é especializada, ou seja, tem domínio sob as técnicas de produção, sendo gerenciada pelo proprietário com 14 colaboradores, distribuídos ao longo das etapas que contemplam as atividades. Normalmente, o processamento ocorre a cada dois meses, de acordo com a necessidade de demanda, que atualmente é de aproximadamente $750 \mathrm{~kg} / \mathrm{mês}$ de erva-mate empacotada.

A especificidade desta análise concentra-se no fato de que a atividade em análise faz uso de procedimentos considerados artesanais (por exemplo: quando efetua o sapeco e o cancheamento ${ }^{18}$ e 0 empacotamento), e também de processos semi-indutriais (e.g., tritura e a moagem).

A produção inicia-se com a colheita da matéria-prima, posterior transporte até a área de produção, onde ocorre a preparação para o "sapeco das folhas" as quais em seguida serão condicionadas no barbaquá, permanecendo por 15 horas (processo de secagem) até que esteja no ponto para ser triturada (erva-mate cancheada), observa-se que este é o primeiro momento de processo mínimo industrial, após estas etapas, a produção estará disponível para ser moída e finalmente empacotada.

Destaca-se, que este estudo pretende analisar a viabilidade econômica para o retorno sobre uma área de 2 (dois) hectares, sendo esta área constituída por aproximadamente 6.600 unidades de planta (3.300 plantas/ha), o qual segundo o proprietário, após 3,5 anos tem a capacidade de produzir o equivalente a $33.000 \mathrm{~kg}$ de erva-mate (peso bruto), observa-se que o espaçamento adotado entre as plantas é de $2 \mathrm{~m} x$ $1,5 \mathrm{~m}$, o qual se busca o adensamento de plantas, diferentemente do modelo tradicional de 2.500 plantas/ha com espaçamento de $2 \mathrm{~m} \times 2 \mathrm{~m}$.

Desta forma, os custos de produção aqui analisados compreendem desde a formação da área (mudas, replantio e manejo) até a data do primeiro corte, contabiliza-se o custo com transporte da matéria prima (combustível); estimam-se os custos da mão de obra (colaboradores) - a qual é calculada considerando o preço médio de uma diária, praticado na região de estudo, multiplicado pelo número de horas necessário ao desempenho de cada etapa do processo (Tabela 2) - e os gastos com energia elétrica, baseando-se na divisão equitativa do número de hora/máquina utilizada conforme dispostos na Tabela 3.

Tabela 3: Estrutura do capital existente e investimentos fixos para a implantação e produção de erva-mate, estimativa de produção para 2 hectares, 3,5 anos de idade e com expectativa de produção de $33.000 \mathrm{~kg} / \mathrm{ha}$ (peso bruto), no município de Amambai, MS, em 2018.

\begin{tabular}{|c|c|c|c|c|}
\hline Item & $\begin{array}{l}\text { Qtd. } \\
\text { Un. }\end{array}$ & $\begin{array}{l}\text { Valor unitário } \\
\text { (R\$) }\end{array}$ & $\begin{array}{l}\text { Valor Total } \\
\text { (R\$) }\end{array}$ & $\%$ \\
\hline \multicolumn{5}{|l|}{ I - Investimento inicial } \\
\hline Erva-mate (mudas) & 6600 & 2,12 & $14.000,00$ & $17,17 \%$ \\
\hline Replantio (20\%) das mudas* & 1320 & 2,12 & $2.748,40$ & $3,37 \%$ \\
\hline Galpão (área coberta e depósito) m² & 55,00 & 472,73 & $26.000,00$ & $31,88 \%$ \\
\hline \multicolumn{5}{|l|}{ II - Máquinas e equipamentos } \\
\hline Veículo de transporte & 1 & $22.000,00$ & $22.000,00$ & $26,97 \%$ \\
\hline Carretinha (reboque) & 1 & $2.390,00$ & $2.390,00$ & $2,93 \%$ \\
\hline Tambora & 1 & $2.200,00$ & $2.200,00$ & $2,70 \%$ \\
\hline Triturador & 1 & $4.500,00$ & $4.500,00$ & $5,52 \%$ \\
\hline Moedor & 1 & $3.000,00$ & $3.000,00$ & $3,68 \%$ \\
\hline Balança & 1 & 150,00 & 150,00 & $0,18 \%$ \\
\hline Soprador & 1 & 220,00 & 220,00 & $0,27 \%$ \\
\hline Hidrolavadora & 1 & 350,00 & 350,00 & $0,43 \%$ \\
\hline Barbaquá & 1 & $4.000,00$ & $4.000,00$ & $4,90 \%$ \\
\hline TOTAL & & & $\mathrm{R} \$ 81.558,40$ & $100 \%$ \\
\hline
\end{tabular}

${ }^{18}$ Redução do volume e forma da erva-mate ou quebramento das folhas e talos para ensacamento antes da trituração final (FRÓES, 2007). 
Ressalta-se que a alocação de recursos, envolve a constante busca pela otimização na aplicação dos recursos visando alcançar a rentabilidade desejada e da mesma forma, preservando-se a capacidade da empresa em pagar seus compromissos nos vencimentos (ASSAF NETO et al., 2014). Entretanto, as empresas configuram suas estruturas de ativos fixos, mantendo essa responsabilidade, mas também prevendo possibilidades de expansão. Isso, em função da demanda de mercado ou parcela de mercado almejado. Observa-se que, conforme dados da pesquisa analisados a partir da Tabela 4, a empresa comercializa 750 $\mathrm{kg} / \mathrm{mês}$ de erva-mate processada, ou seja, necessita manter uma produção anual de $9.000 \mathrm{~kg}$ de erva. Segundo perspectivas do proprietário a pretensão é atingir o volume de 18.000 kg de venda/ano.

Tabela 4: Estimativa do Custo Operacional para produção (plantio e processamento) de erva-mate - área de 2 (dois) ha, no município de Amambai, Estado de Mato Grosso do Sul -perspectiva estimada de colheita em 3,5 anos de 33.000 $\mathrm{kg} / \mathrm{ano}$ (peso bruto) de erva-mate in natura.

\begin{tabular}{|c|c|c|c|}
\hline \multicolumn{4}{|c|}{ Primeiro corte * } \\
\hline Etapas & Item & $\begin{array}{l}\text { Custo Total } \\
(\mathrm{R} \$)\end{array}$ & $\% \mathrm{COE}$ \\
\hline 1 & Manutenção por hectare ${ }^{1}$ & $\mathrm{R} \$ 7.200,00$ & $11,44 \%$ \\
\hline \multicolumn{4}{|c|}{ Etapas de produção } \\
\hline 2 & Combustível ${ }^{2}$ (qtd x preço litro) & $R \$ 3.600,00$ & $5,72 \%$ \\
\hline 3 & $\begin{array}{l}\text { Mão de obra - colheita manual; transporte; "sapeco"; secagem no barbaquá; } \\
\text { "cancheamento"; trituração, e; empacotamento }{ }^{3} \text {. }\end{array}$ & $\mathrm{R} \$ 21.690,00$ & $34,46 \%$ \\
\hline 4 & Energia elétrica ${ }^{4}$ & $\mathrm{R} \$ 5.252,40$ & $8,34 \%$ \\
\hline 5 & Outras despesas ${ }^{5}$ & $\mathrm{R} \$ 9.196,10$ & $14,61 \%$ \\
\hline \multicolumn{2}{|c|}{ Custo operacional efetivo (COE) } & $\mathrm{R} \$ \mathbf{4 6 . 9 3 8 , 5 0}$ & $74,57 \%$ \\
\hline 6 & Depreciação de máquinas $^{6}$ & $\mathrm{R} \$ 8.848,00$ & $14,06 \%$ \\
\hline 7 & Encargos sociais e trabalhistas ${ }^{7}$ & $\mathrm{R} \$ 7.157,70$ & $11,37 \%$ \\
\hline \multicolumn{2}{|c|}{ Custo operacional total (COT) } & $\mathrm{R} \$ \mathbf{6 2 . 9 4 4 , 2 0}$ & $100,00 \%$ \\
\hline \multicolumn{2}{|c|}{ COT por quilogramas } & $R \$ 4,96$ & - \\
\hline \multicolumn{4}{|c|}{$\begin{array}{l}\text { *Após } 3,5 \text { anos, inicia-se o processo de colheita, denominada } 1^{\text {a }} \text { poda de produção. Estima-se que cada planta produza o equivalente a } 5 \mathrm{~kg} \text {, } \\
\text { totalizando um volume de } 33.000 \mathrm{~kg} \text { de erva-mate in natura para uma área de } 2 \text { hectares. Para este volume a empresa acionaria, aproximadamente } \\
18 \text { vezes a sua estrutura produtiva, alcançando uma produtividade líquida de } 12.692 \mathrm{~kg} \text {. Fórmula: } 3.300 \text { plantas X } 5 \mathrm{~kg} / \mathrm{plantas} \times 2 \text { ha dividido por } \\
1800 \mathrm{~kg} \text { (capacidade do barbaquá). }\end{array}$} \\
\hline \multicolumn{4}{|c|}{${ }^{1}$ Custos de manutenção para 2 ha com 3.300 und/ha ao custo de $R \$ 3.600,00$ ano/ha - estima-se um custo mensal de $R \$ 300,00 /$ mês com diárias. } \\
\hline \multicolumn{4}{|c|}{${ }^{2}$ Gastos com o transporte da matéria prima da lavoura ao parque de produção. Fórmula: $R \$ 200,00$ x 11 (qtd. de operações). } \\
\hline \multicolumn{4}{|c|}{$\begin{array}{l}{ }^{3} \text { As etapas de processamento envolvem } 14 \text { colaboradores, havendo um adicional ao mestre ervateiro e seu auxiliar (diária de } R \$ 60,00+R \$ 200,00 \\
\text { mestre ervateiro e auxiliar), multiplicado por } 11 \text {. }\end{array}$} \\
\hline \multicolumn{4}{|c|}{$\begin{array}{l}4 \text { Para efeito de cálculos, considera-se: } \$ 15,00 \text { multiplicado por } 11 \text {, e; consumo na trituração por barbaquá e R\$0,20 para cada quilograma no } \\
\text { processo efetuado no moinho. }\end{array}$} \\
\hline \multirow{2}{*}{\multicolumn{4}{|c|}{$\begin{array}{l}{ }^{5} \text { Neste somatório inclui: } 346 \text { unidades de sacarias com capacidade média de } 22 \mathrm{~kg} / \mathrm{saca} \text { ao custo de } \mathrm{R} \$ 1,50 \text { unitário - Fórmula de cálculo: } 12.692 \mathrm{~kg} \\
\text { / } 22 \mathrm{~kg} / \mathrm{sc} X \mathrm{R} \$ 1,50 \text {; custo de empacotamento } \mathrm{R} \$ 0,55 \text { x quantidade produzida e; custos com aquisição de lenha ( } \mathrm{R} \$ 75,00 \text { para } 4 \text { mts }{ }^{3} \text { multiplicado } \\
\text { por 11). }\end{array}$}} \\
\hline & & & \\
\hline \multicolumn{4}{|c|}{$\begin{array}{l}{ }^{6} \text { Para o cálculo da depreciação utiliza-se o método linear ou depreciação constante ( } 20 \% \text { para veículos e } 10 \% \text { para Instalações e Máquinas e } \\
\text { equipamentos). }\end{array}$} \\
\hline & sociais e trabalhistas referem-se a $33 \%$ do valor da mão de obra (férias, 13으, INSS, etc.). & & \\
\hline
\end{tabular}

A estimativa de custo operacional total (COT), para o cultivo em dois hectares de erva-mate, e todos os custos correlacionados à atividade é de $\mathrm{R} \$ 62.944,20$ ao final de 3,5 anos, incluindo-se aqui, os custos de manutenção (manejo) dos anos 2 (dois) e 3 (três). Havendo então a necessidade de a empresa dispor de recursos financeiros que financie o manejo da cultura (limpeza, replante e mão de obra), as quais totalizam aproximadamente $\mathrm{R} \$ 3.600,00 /$ ano para cada hectare. Neste período a empresa não faz uso do seu parque de produção, caso contrário os resultados econômicos sofreriam alterações.

Se somados, os valores apresentados na mão de obra $(R \$ 21.690,00)$ e nos encargos sociais e trabalhistas $(R \$ 7.157,70)$ representam $45,83 \%$ do COT, indicando o principal custo nesta atividade, que demandam profissionais com conhecimento técnico específico. 
Havendo a produção estimada de 33.000 kg de peso bruto na primeira "poda de produção" a empresa operacionalizaria sua estrutura de produção 18 vezes (cálculo aproximado, em função da capacidade de processamento no barbaquá - $1800 \mathrm{~kg}$ ). Sendo, esta capacidade de produção que norteou os demais custos (combustível, mão de obra, energia elétrica, sacarias, embalagem lenha destinada ao cancheamento).

O custo operacional total por quilograma (COT/kg) produzido ficou em $\mathrm{R} \$ 4,96$. O preço de venda praticado pelo proprietário é de $\mathrm{R} \$$ 8,00 o quilograma. Importante ressaltar que o preço aqui apresentado, difere de algumas literaturas que direcionam o cálculo considerando o preço da arroba. Assim, o preço formatado e informado em quilograma $(\mathrm{kg})$ se deve pela especificidade do produto, considerado "artesanal".

Na Tabela 5 estão contidas as margens de retorno e lucratividade anual obtidos com a atividade, considerando o volume de produção para a 1ạ poda ou poda de formação (aos 3,5 anos), conforme anteriormente informado.

Tabela 5: Margem de retorno e Lucratividade - anual.

\begin{tabular}{|c|c|c|c|c|}
\hline Qtd. produzida (kg) & Preço de venda (R\$/kg) & (=) Receita Bruta (R\$) & (-) Custo Operacional Total (COT - R\$) & (=) Lucro antes do IR (R\$) \\
\hline 12.692 & 8,00 & $101.536,00$ & $-62.944,20$ & $38.591,80$ \\
\hline \multicolumn{2}{|l|}{ СОT por quilograma } & $\mathrm{R} \$ 5,86$ & $\mathrm{R} \$$ & $\begin{array}{l}\text { Lucratividade = } \\
\text { LL/RO }\end{array}$ \\
\hline \multicolumn{5}{|c|}{ DEMONSTRAÇÃO DE RESULTADO - PROJETADO } \\
\hline \multicolumn{2}{|c|}{ Receita Operacional (RO) } & & $101.536,00$ & \\
\hline \multicolumn{2}{|l|}{ Custos operacionais } & & (-) 62.944,20 & Lucratividade de \\
\hline \multicolumn{2}{|l|}{ (=) Lucro antes do IR } & & $38.591,80$ & $25,845 \%$ a.a. \\
\hline \multicolumn{2}{|c|}{ (-) Provisão para IR e Contribuição Social } & & (-) $12.349,38$ & \\
\hline \multicolumn{2}{|c|}{ (=) LUCRO LÍQUIDO DO EXERCÍCIO (LL) } & & $\Leftrightarrow) 26.242,42$ & \\
\hline
\end{tabular}

Na sequência da análise torna-se importante a inclusão da Tabela 6, para demonstrar o tempo estimado do retorno do aporte de investimentos ao longo do tempo considerado.

Ressalta-se que o resultado apurado no 1 으의o perío tem sua origem de acordo com volume de produção para plantas de 3,5 anos, ou seja, $5 \mathrm{~kg} /$ unidade planta. Desta forma, no segundo período de colheita (que ocorre 2 anos a partir do 1을 corte), a planta terá o seu volume de produção aumentado para aproximadamente $8 \mathrm{~kg} / \mathrm{un}$. O que viabilizaria um melhor aproveitamento da capacidade produtiva da empresa diminuindo, consequentemente, o Custo Operacional Total por quilograma, que resultaria em $\mathrm{R} \$ 4,61$. Modificando positivamente a projeção de retorno para os anos seguintes, representado por um retorno líquido de $\mathrm{R} \$ 46.764,38$. Para fins de cálculos foram considerados os fluxos de receita para os três períodos de análise, sendo considerado o valor do terceiro ano para os demais períodos, contidos na Tabela 6.

Tabela 6: Tempo estimado do retorno do investimento aplicado (Payback Simples) e fluxos de caixa.

\begin{tabular}{|c|c|c|}
\hline ANO & FLUXO DE CAIXA (FC) & FC (ACUMULADO) \\
\hline 0 & $-\mathrm{R} \$ 144.502,60$ & $-\mathrm{R} \$ 144.502,60$ \\
\hline 10 corte (3,5 anos) & $\mathrm{R} \$ 26.242,42$ & $-\mathrm{R} \$ 118.260,18$ \\
\hline $2 \circ$ corte $(5,5 \text { anos })^{*}$ & $R \$ 46.764,38$ & $-R \$ 71.495,80$ \\
\hline 3o corte $(7,5 \text { anos })^{*}$ & $\mathrm{R} \$ 46.764,38$ & $-R \$ 24.731,42$ \\
\hline 40 corte $(9,5 \text { anos })^{*}$ & $\mathrm{R} \$ 46.764,38$ & $\mathrm{R} \$ 22.032,96$ \\
\hline
\end{tabular}


A ferramenta utilizada se denomina payback simples, a qual tem por finalidade, indicar o tempo estimado em que ocorrerá o retorno do investimento aplicado, considerando um fluxo de caixa permanente. O Fluxo de Caixa para o "Ano 0" considera os valores totais de investimento (capital fixo e os custos de produção compreendidos entre o plantio e respectivo (OT). Para os demais fluxos, consideraram-se os resultados (líquidos) para cada período, já descontados o imposto de renda na alíquota de $32 \%$ para empresas optantes do Lucro Real.

O resultado mostra que, para um investimento total $R \$ R \$ 144.502,60$ direcionados para uma lavoura permanente de erva-mate, em dois hectares, mais estrutura de ativos fixos e também dos custos de manejo, a empresa cobriria o investimento no quinto ano de colheita, ou seja, considerando o tempo de espera para a primeira colheita, o investimento passaria a dar retorno financeiro a partir de 9,5 anos (considera-se o período de 3,5 anos para a primeira poda, somados aos 6 anos previstos no payback). Ressalta-se que para este estudo, a partir da terceira poda, considerou-se uma produção de $6 \mathrm{~kg}$ de erva-mate in natura para cada unidade/planta.

Sabe-se, no entanto, que o payback simples não considera em seu cálculo o custo do capital ou a TMA, impossibilitando uma melhor leitura do tempo de retorno. Justificando a aplicação do cálculo do Valor Presente Líquido, uma vez que este considera o custo do capital (TMA 20\%a.a.) empregado na atividade. Assim, considerando o fluxo de caixa trazido a Valor Presente (VPL) obtêm-se um retorno de 6.962,27 (seis mil, novecentos sessenta e dois reais e vinte sete centavos) para o 7ํ corte. Assim também o cálculo da Taxa Interna de Retorno (TIR), considerando a mesma estrutura (custo e fluxo), indica um resultado de $21,61 \%$ a.a.

Por outro lado, a lucratividade indicada em cálculo contido na Tabela 5 apresenta o valor de 25,85\% a.a. O mesmo cálculo quando efetuado para os demais exercícios apontam para $28,79 \%$ a.a. o que denota bons números para a atividade, sugerindo a continuidade da unidade produtiva e possível expansão do empreendimento.

\section{CONCLUSÕES}

Os resultados mostraram a viabilidade econômica da erva-mate para a área do estudo, com os percentuais expressos na lucratividade ( $L L=25,85 \%$ a.a. e TIR $21,61 \%$ a.a. e TMA $20 \%$ a.a.). No entanto, a viabilidade econômica deve ser pensada como uma atividade alternativa, uma vez que o cultivo é considerado como investimento ex-post, ou seja, o tempo de retorno dos investimentos é longo e suscetível a diversos fatores, tanto endógenos como exógenos.

O produtor deve considerar o tempo necessário para o retorno do investimento, analisado de forma conjunta com as demais atividades da propriedade. Neste caso, o investimento será coberto a partir da sétima poda (folha e galhos finos). As bases de iniciativas dos sistemas agroindustriais, principalmente aqueles inseridos em sistemas agroflorestais, remetem para a necessidade de ampliar as informações de investimentos e retornos financeiros a pequenos e médios produtores dos municípios brasileiros ao longo da fronteira Brasil e Paraguai, que compreendiam no passado, extensas áreas nativas de erva mate no Estado 
de Mato Grosso do Sul.

\section{REFERÊNCIAS}

ABINZANO, R. C.. "El frente extractivo de yerba mate y madera: una actividad socioeconómica transnacional de la triple frontera" In: NÚNES A.; PADOIN M. M.; OLIVEIRA, T. C. M.. Dilemas e diálogos platinos: relações e práticas socioculturais. Dourados: UFGD, 2010.

ASSAF NETO, A. A.. Estrutura e Análise de Balanços: um enfoque econômico-financeiro. 6 ed. São Paulo: Atlas, 2001.

ASSAF NETO, A.; LIMA, F. G.. Curso de Administração Financeira. 3 ed. São Paulo: Atlas, 2014.

BATALHA, M. O.. Gestão Agroindustrial. GEPAI: Grupo de Estudos e Pesquisas Agroindustriais. 3 ed. São Paulo: Atlas, 2008.

BIACHINI, O. C. D.. A companhia Matte Larangeira e a ocupação da terra do sul de Mato Grosso: (1880-1940). Campo Grande: UFMS, 2000.

BRANDT, M.; SILVA, N. S.. A coleta da erva-mate pela população cabocla do Vale do Rio do Peixe e oeste de Santa Catarina: apropriação privada da terra e rupturas (décadas de 1900 a 1940). Sociedade \& Natureza, Uberlândia, v.26, n.3, 2014. DOI: http://dx.doi.org/10.1590/1982$\underline{451320140305}$

CIMÓ, P. R. C. Q.. A Companhia Matte Laranjeira, 1891-1902: contribuição à história da empresa concessionária dos ervais do antigo sul de Mato Grosso. Revista Territórios \& Fronteiras, Cuiabá, v.8, n.1, 2015. DOI: http://dx.doi.org/10.22228/rt-f.v8i1.336

DALLABRIDA, V. R.; SANTOS, F. T.; PETRENTCHUK, L. W.; SAKR, M. R.; BARBOSA, M. Z.; ZEITHAMMER, N.; MOREIRA, P.; SCOLARO, T. L.; MARCHESAN, J.. Indicação geográfica da erva-mate no território do contestado: reflexões e projeções. DRd - Desenvolvimento Regional em Debate, v.4, n.2, p.44-77, 2014. DOI:

http://doi.org/10.24302/drd.v4i2.728

DANIEL, O.. Erva-mate: sistema de produção e processamento industrial. Dourados: UFGD; UEMS, 2009.

FAO. Food and Agriculture Organization of the United Nations. Global Forest Resources Assessment 2015. Desk reference. Rome: FAO, 2015.
FRÓES, M. B.. Os caminhos da erva-mate na fronteira sulmato-grossense. Maringá: Massoni, 2007.

GRESSLER, L. A.; VASCONCELOS, L. M.. Mato Grosso do Sul: Aspectos históricos e geográficos. Dourados, 2005.

IBGE. Instituto Brasileiro de Geografia e Estatística. Produtos de Extração Vegetal e de Silvicultura. Rio de Janeiro: IBGE, 2017.

IBGE. Instituto Brasileiro de Geografia e Estatística. Lavouras permanentes. Rio de janeiro: IBGE, 2017.

KREUZ, C. L.; SOUZA, A.; STADLER, H.. Rentabilidade de ervais nativos na região dos Campos de Palmas-PR In: EGEPE - ENCONTRO DE ESTUDOS SOBRE EMPREENDEDORISMO E GESTÃO DE PEQUENAS EMPRESAS, 4. Anais. Curitiba, 2005, p.30-41.

LEITE, J. S. J.; PADOVEZE, C. L.; BENEDICTO, G. C.. Manual de Gestão e Controle de Ativos Imobilizados: critérios, procedimentos e práticas contábeis, fisco-tributários e de gestão. São Paulo: IOB Sage, 2016.

MACCARI JUNIOR, A.. Análise do pré-processamento da erva-mate para chimarrão. Tese (Doutorado em Engenharia Agrícola) -Universidade Estadual de Campinas, Campinas, 2005.

MARCONI, M. A.; LAKATOS, E. M.. Metodologia científica. 6 ed. São Paulo: Atlas, 2011.

RODIGHERI, H. R.; GRAÇA, L. R. Lucratividade da acácianegra, bracatinga, erva-mate e eucalipto no sul do Brasil. Revista Extensão Rural, v.9, 2002. DOI: http://doi.org/10.5902/23181796

SHAEFFER, R. O.. Manejo Florestal em Áreas de Reserva Legal. Campo Grande: UNIDERP, 2003.

SIMÕES, A. R.; MOURA, A. D.; ROCHA, D. T.. Avaliação econômica comparativa de sistemas de produção de gado de corte sob risco no Mato Grosso do Sul. Revista de Economia e Agronegócio, Viçosa, v.5, n.1, 2007. DOI: http://locus.ufv.br//handle/123456789/20032

YIN, R. K.. Estudo de caso: planejamento e métodos. 2 ed. Porto Alegre: Bookman, 2001.

A CBPC - Companhia Brasileira de Produção Científica (CNPJ: 11.221.422/0001-03) detém os direitos materiais desta publicação. Os direitos referem-se à publicação do trabalho em qualquer parte do mundo, incluindo os direitos às renovações, expansões e disseminações da contribuição, bem como outros direitos subsidiários. Todos os trabalhos publicados eletronicamente poderão posteriormente ser publicados em coletâneas impressas sob coordenação da Sustenere Publishing, da Companhia Brasileira de Produção Científica e seus parceiros autorizados. Os (as) autores (as) posteriormente ser publicados em coletâneas impressas sob coordenação da Sustenere Publishing, da Companhia Brasileira de Produção Científica e seus parce
preservam os direitos autorais, mas não têm permissão para a publicação da contribuição em outro meio, impresso ou digital, em português ou em tradução. 